The CDC currently provides staffTRAK-TB technical support to the hospitals and health departments involved in its collaborative projects. Additional availability of the software will be determined based on feedback from current users, potential for other interested users, and availability of resources at the $\mathrm{CDC}$ to support additional users. Limited copies of the user's manual and software, without any technical support, may be available from the Division of Tuberculosis Elimination, Centers for Disease Control and Prevention, Mailstop E10, 1600 Clifton Rd NE, Atlanta, GA 30333, telephone (404) 639-8117.

\section{REFERENCES}

1. Centers for Disease Control and Prevention. Guidelines for preventing the transmission of Mycobacterium tuberculosis in health-care facilities, 1994. MMWR 1994;43(RR-13):1-132.

2. Bureau of the Census. 1990 Census of Population and Housing: Classified Index of Industries and Occupations. Washington, DC: Bureau of the Census, US Department of Commerce; 1992.

3. Centers for Disease Control and Prevention. NNIS Manual: National Nosocomial Infections Surveillance System. Atlanta, GA: Centers for Disease Control and Prevention; 1988.

4. Burwen DR, Seawright MF. Challenges in electronic importing of health data. Journal of Public Health Management and Practice. In press.

5. American Thoracic Society, Centers for Disease Control. The tuberculin skin test. Am Rev Respir Dis 1981;124:356-363.

\title{
Mycobacterium tuberculosis From Whirlpools
}

\section{Gina Pugliese, RN, MS Martin S. Favero, PhD}

Mycobacterium species are recognized for their ability to cause respiratory disease in healthy and immunocompromised individuals. Recent evidence has implicated certain species as antigenic agents involved in the development of hypersensitivity pneumonitis ([HP] extrinsic allergic alveolitis). Mycobacterium chelonae reservoirs in metal working fluids have been suggested as etiologic agents of occupationally acquired HP. Similarly, recent reports have associated Mycobacterium avium with $\mathrm{HP}$ acquired by individuals using hot tubs contaminated with $M$ avium complex. Investigators from NIOSH responded to two separate requests for technical assistance to investigate the possible contributions of generated aerosols from therapy pools

The prevalence of colonization by vancomycin-resistant enterococci (VRE) in various population groups in Berlin was investigated by Wendt and colleagues from the Institut fur Hygiene, Umweltmedizin und Arbeitsmedizin Freie Universitat Berlin. In a cross-sectional study, rectal swabs were taken from seven population groups (healthy students, outpatients, home nursing patients, normal care and critical-care patients of a community hospital and university hospital). Everyone completed a questionnaire (age, gender, previous hospital stays, antibiotic therapy). Rectal swabs and whirlpools to the development of occupationally acquired HP. These pools were all heated and used a combination of ultraviolet germicidal irradiation (UVGI) with hydrogen peroxide to reduce the microbiological load in the water. In the whirlpool study, chlorine-treated pools from the same facility were evaluated for comparison. Environmental evaluation consisted of the collection of bulk water samples and air samples to be analyzed for mycobacterial and endotoxin content.

Bulk sample analysis revealed significant mycobacterial contamination (ranging to $>6,000$ colonyforming units $/ \mathrm{mL}$ ) of therapy whirlpool waters compared with nondetectable concentrations in the waters treated with chlorine. The presence of mycobacteria was confirmed by polymerase chain reaction (PCR) analysis. Culturable air samples and PCR analysis resulted in signifi-

\section{VRE Colonization in Berlin}

were examined for the presence of normal gut flora and VRE. All VRE isolates were typed by pulsed-field gel electrophoresis (PFGE).

VRE colonization prevalence ranged from $0.9 \%$ (students) to $4.2 \%$ (nursing home patients) in nonhospitalized subjects; in hospitalized patients, prevalence ranged from $1.8 \%$ (regular-care ward of a community hospital) to $16.3 \%$ (intensive care unit patients of a university hospital). Location (university hospital, $\mathrm{OR}=3.5$ ) and age ( $>60$ years, $\mathrm{OR}=2.2$ ) were independent risk factors for VRE colonization. Within one popula- cant concentrations at locations around therapy pools and whirlpools, while those observed in the control locations had no detectable levels. PCR analysis resulted in productive information when, in limited situations, cultured plates were destroyed by fungal overgrowth. The use of the studied UVGI and hydrogen peroxide disinfection systems may have resulted in the amplification of mycobacteria due to limited competition with other bacterial species resulting from inactivation or kill.

FROM: Martinez KF, Schafer MP, Seitz TS. The detection and characterization of airborne dissemination of Mycobacterium species from contaminated therapy pools and whirlpools. Presented at Hazard Control Technologies in Healthcare: Collaborative Strategies for the Next Millennium; August 2-4, 1999; Colorado Springs, CO. Abstract $1 \mathrm{C} 2$. tion group, isolates with identical PFGE patterns were found in up to three people; one strain was found in four subjects belonging to different groups. The authors conclude that their findings suggest that VRE are imported from the community into hospitals with subsequent spread within the institution.

FROM: Wendt C, Krause C, Xander LU, Loffler D, Floss H. Prevalence of colonization with vancomycin-resistant enterococci in various population groups in Berlin, Germany. J Hosp Infect 1999;42: 193-200. 